\title{
Incentive Contracts for Road Construction to Reduce Greenhouse Gas Emissions
}

\author{
Mathagul Metham a and Vacharapoom Benjaoran ${ }^{\mathrm{b}, *}$ \\ School of Civil Engineering, Suranaree University of Technology, Nakhon Ratchasima 30000, Thailand \\ E-mail: aD5740178@g.sut.ac.th, bvacharapoom@sut.ac.th (Corresponding author)
}

\begin{abstract}
Road constructions play a significant role in greenhouse gas (GHG) release into the atmosphere due to a large amount of materials consumption. To reduce emission has an effect on project costs. This research proposes an incentive measure named the Construction-Emission-Punishment (CEP) bidding method which offers emission reduction options and incentives for participating bidders. An equivalent bid price and a financial penalty will be specified in the construction contract as a part of this method. This penalty is applied when there is a failure to comply with binding obligations. The results show that the rates of the emission deduction from the six reduction options account for $0.115 \%-2.768 \%$ of the project cost. The case study also shows that a bidder who receives some emission deductions can be the winner. The effectiveness of the CEP method depends on the bid price gaps among the bidders and the emission deduction from the selected options.
\end{abstract}

Keywords: Bidding, incentives, emissions, greenhouse gas, road construction.

ENGINEERING JOURNAL Volume 22 Issue 5

Received 7 January 2018

Accepted 17 July 2018

Published 30 September 2018

Online at http://www.engj.org/

DOI:10.4186/ej.2018.22.5.105 


\section{Introduction}

Greenhouse gases (GHGs) are mainly responsible for the global warming issue [1, 2]. According to the GHG emissions ranking, the United States has been placed second behind China's emission level [1]. Energy consumption has been a key cause and the highest emissions sector. The construction industry ranks in the third highest emitter which accounts for $1.8 \%$ of the total of the U.S. GHG production [3]. Energy supplies were the main cause for developing countries to generate approximately $11.5 \%$ of global emissions between 1970 and 2004 [4]. Additionally, in Thailand, a report states that the energy sector has emitted the most GHGs, at about $13.4 \%$ of the total of Thailand's GHG production [5] while the manufacturing and construction industry is the third highest emitter. Most of the increasing GHG releases are caused by anthropogenic activities - mainly due to an increase in fossil energy consumption. Activities in construction projects, especially road constructions, require a great deal of energy, materials and equipment consumptions [6]. In 2006, road construction projects of the U.S. Interstate Highways used 1.5 billion metric tons of crushed rock aggregates, 35 million metric tons (Mt) of asphalt, $48 \mathrm{Mt}$ of cement, and $6 \mathrm{Mt}$ of steel in order to provide 73,000 kilometers of the highway system [7].

Undoubtedly, some construction stakeholders have been aware of this issue. As a result, made an effort to reduce the GHG emissions caused by anthropogenic activities. Several actions, depending on the characteristics of the construction works, have been carried out to alleviate this issue. For example, some building construction projects have attempted to deal with such emissions by focusing on inventing and innovating construction materials that consume less energy and/or produce less emission than conventional materials [8]. Road construction projects have also been carried out using more efficient management of energy, materials, and equipment consumptions $[9,10]$ and replaced dated models of machinery by newer ones. This includes installation of retrofit devices. Cass and Mukherjee [11] studied the possible GHG emission reductions at the construction phase of a road construction project by using the hybrid LCA approaches. Also, Santero et al. [12] have found that GHG releases were decreased by $10 \%$ when avoiding the negative effects of materials and by reducing the fuel consumptions of concrete pavement constructions. Nonetheless, road contractors have rarely used these reduction approaches in practice due to the lack of any incentives and benefits [9] so worthwhile benefits have to be offered to road contractors to encourage the participation. Puri and Tiwari [13] found that the project owners could achieve this by placing additional requirements in the bid evaluation criteria.

Hence, this study proposes incentive measures for road construction that encourages the reduction of GHG emissions through the bidding and contract-enforcing methods named Construction-EmissionPunishment (CEP). A surplus benefit and a modified bid evaluation should potentially lead to more participation. A privileged incentive offered to bidders plays an important role in this measure. The bidding process is targeted because it can push the awarded contractors to follow the GHG reduction operations through the contractual obligations. Some historical road construction projects in Thailand are used as case studies to demonstrate the application of the CEP method.

\section{Related Literature}

\subsection{Emissions Evaluation of Constructions}

Environmental impacts of the production of goods require an evaluation approach that is both reliable and internationally accepted. One of the widespread approaches of greenhouse gas emissions evaluation is the life cycle assessment (LCA) [14], according to the International Organization for Standardization (ISO) 2006 standard series: ISO14040: 2006 and ISO14044: 2006 [15]. The LCA approach is performed by converting the input data of each product's activity to its environmental impact. Materials and energy consumption of all products' processes are used as the input data. The processes are comprised of the extraction of raw materials, the manufacturing of materials and/or energy and the operation, and maintenance as well as the disposal or the recycling of the products or services. This approach can be evaluated in term of the environmental impacts of the construction activities as well $[16,17]$. The LCA uses several methods, i.e. a process-based method, an input-output (I-O) based method and a hybrid method. The suitability of adopting the LCA method depends on how complicated and complete the data are. Generally, hybrid LCA has been deemed appropriate for construction work whose manufacturing of materials stage was evaluated by the I-O 
based method, while the construction and the transportation stages are usually evaluated by the processbased method [16].

\subsection{Emissions Reduction in Constructions}

Several strategies can be used to achieve the GHG emissions reduction. The government has launched some campaigns to encourage collaborations and participations in reducing the selves-emissions. For instance, the energy consumption in residences can be reduced to sufficient levels; the energy consumption in organizations can also be managed more efficiently; and fossil fuels can be substituted by more renewable and cleaner energy. As a part of these efforts, the EPA [18] has recommended several guidelines on reducing the emissions such as maintaining machinery frequently and punctually, installing retrofit devices, acquiring newer machinery and using low-sulfur fuel and/or biodiesel fuel. These operations follow the GHG reduction strategies arose not only from the voluntary parties who complied without compulsion but also from the parties who were forced to comply with the regulations.

Eštoková and Porhinčák [8] compared conventional materials to the alternative materials of a building construction project. This study revealed that the substitution of alternative materials affected the emission levels. To reduce the emissions in road construction, Ahn et al. [9] proposed five mitigation options, comprising the replacement of old equipment, an installation of retrofit devices, a fossil fuel substitution with biodiesel (B20), a replacement with hybrid machinery and a change of the materials sources to nearer sources. However, biodiesel is commonly used in the form of many blends, varying from B2 to B20 across the globe $[19,20]$. In addition, Ahn et al. [9] recommended the replacement of machinery for the whole fleet and the installation of retrofit devices but these requirements would create excessive costs to the contractors. However, the approaches can be partially implemented depending on it being affordable to the participants.

Another example of how to reduce the emission in road construction comes from a study by Metham and Benjaoran [21]. The study evaluated different construction techniques of a base course and their associated environmental impacts. These techniques were employed in accordance with the standards for highway construction of the Thailand's Department of Highways (DOH). The results revealed that the dated construction techniques contributed to various negative environmental impacts. Therefore, it is worthwhile conducting research to mitigate these environmental impacts.

\subsection{Green Public Procurement for Construction Project}

GHGs emission becomes a particularly noteworthy issue. One of an adaptation is green public procurement (GPP) for a construction contract. Encouragement of governments has also adapted to establish an environmental innovation. For instance, Cui et al. [22] evaluated to solve the GHGs emission in a road construction project to Maryland State Highway Administration. The main objectives are: emission reduction and global warming adaptation, environmentally positive effect, and develop human life (economic, society and environment), which lead to a delivery for sustainable into a construction contract. There are seven evaluation criteria that include: 1) emission reduction potential, 2) financial consideration, 3) technological maturity, 4) organizational readiness, 5) industrial and public acceptance, 6) risk, and 7) impact on project performance. These criteria were defined in a decision-making model, named, Green Performance Contracting (GPC) that were used to select an appropriate green and sustainable performance contracting. A part of this implementation alternative, for instance, reclaimed asphalt pavement (RAP), equipment retrofitting, alternative fuels, etc. This established strategy shows that the owner also ready to adapt their performance conditions to alteration context.

Adriana et al. [23] proposed a green procurement framework for evaluating a contractor of a road construction project in Australia. This is based on interviews and procurement documents across five Australian states. This framework determines seven procurement stages for green procurement incentives throughout the delivery of a road construction project. Evaluation procedures attempt to persuade for proactively motivating behavioral change. These efforts is a green path to a sustainable contracting. The GPP is an evidence that it widely applies to meet environmental sustainability. There are not only Australian construction projects but also Malaysian [24] and Swedish construction industry [25].

Hence, a public's incentive contracting for a contractor qualification can adapt to serve special conditions, according to owner requirements. Besides, the incentive contracting not only provide a bid cost competition but also an extra requirement (quality of product and/or environment) that would convince contractors involved. The great response of the contractors, however, a worthwhile of return benefit is also an important 
deliberation of an incentive contracting [26]. There is little doubt as to the valuable of such an investment. Therefore, this concern has also become aware of the green contract that will be proposed in this study.

\subsection{Incentive Contract of Construction}

In recent years, many developments in new highway contracting methods have emerged from a combination of construction costs, time and quality [27]. The contracting method depends on some specific objectives of owners and contractual obligations for contractors. The incentives/disincentives determine the nature of the contract by providing a bonus or a penalty depending on how early or late the projects are delivered $[28,29]$. In terms of incentive/disincentive contracts, a condition of a rental fee surcharge is included in some lane rental contracts. The surcharge is based on an estimated cost of the road users' delay. One interesting example of this innovative contract was proposed by the U.S. Department of Transportation (DOT) as cost plus time or named $\mathrm{A}+\mathrm{B}$ bidding contract as shown in Eq. (1):

$$
\text { Total Bid }=A+(B \times R U C)
$$

where $\mathrm{A}=$ bidders' estimated cost

$\mathrm{B}=$ time bid

RUC $=$ daily road user cost, as furnished by the owner.

The time bid is the estimated time to complete the project by bidders. The time bids of each bidder are multiplied by a road user cost in monetary units per day. Moreover, an $\mathrm{A}+\mathrm{C}$ bidding contract was defined for environmental purpose. The $C$ term instead of $B$ is environmental cost in monetary units per kilogram unit of gas mass [9]. The combination of both values is the total bid. This contract considers the bid cost and time cost altogether. The bidder who proposes the lowest combined cost will be the winner. These incentive/disincentive contracts have been implemented and they have achieved a great success [30, 31].

Ahn et al. [9] considered the bid cost based on the A+C bidding contract. Their study combined the construction cost with the eco-costs. This type of costs has become a part of the contractor selection criteria. The eco-cost which was initially introduced by Vogtländer [32] was the costs converted from mitigation options or prevention measures. Obviously, these reduction options will increase the expenses of the project so a compensatory benefit should be offered in order to balance the cost of added responsibility. The CEP bidding method has been initiated and adopted according to these concepts.

\section{CEP Bidding Method}

This research initiates the CEP bidding method which is adapted from the conventional bidding method. The CEP method emphasizes the collaboration of contractors in reducing emissions in public road construction projects. A framework of the CEP method comprises six steps. The first to fourth steps are performed in the bidding phase while the fifth and sixth steps occur in the post-bidding phase. The details of these six steps are described as follows:

- Submission of construction bid: After all participant bidders estimate their own project prices based on the bill of quantity (BOQ), they have to submit their bid prices called Construction Bids (C) and enter into the bid competition. The government as a project owner has prepared their own estimate before. This estimate is called Owner's estimated cost (OC). Normally, the government limits their budget for a construction project to the OC.

- Submission of a proposal of reduction options: The bidders propose their own preference options for emission reduction together with the $\mathrm{C}$ on the bid date. The proposal should indicate the chosen options (from the six options available, which will be detailed later in this paper) and their associated parameters such as total amount of the biodiesel and preference blend formula between B5-B20, hauling distance of materials, total amount of base course material, an amount of the newer model machinery replacement than Tier3, an amount of the hybrid machinery replacement, the retrofit device installations, horsepower of machinery each type, and work hour each machinery, etc.

- Emission deduction calculation: All proposed options of each bidder in step 2 are used to estimate the value of GHG credits and then converted into a monetary term called Emission Deduction (E) according to Eq. (2) to (21). 
- Equivalent bid calculation: Equation (22) is simply used to calculate the Equivalent Bid (Q). Then, all bidders' Qs are compared in the bid evaluation procedure, instead of Cs. The first criterion is to award the lowest Q. In the case that several bidders offer equal lowest Qs, the highest $\mathrm{E}$ among them will become the next criterion for consideration.

- Field monitoring: This step is performed after the award of the contract. The winning bidder becomes the contractor and executes the construction work. They have an additional contractual obligation to carry out the reduction options as previously proposed. The achievement of the contractor is investigated and evidenced via the site monitoring and the data collection. If the contractor fails to fulfill the proposed options, they will be penalized.

- Penalty and Payment calculations: The amount of a Penalty (Pe) is calculated by using Eq. (23). Also, the project payment $(\mathrm{Pa})$ which is calculated according to Eq. (24) is totally equal to the Construction Bid (C) subtract with the Penalty (Pe). The total amount is gradually paid to the contractor.

The CEP procedures include five monetary terms, namely Construction Bid (C), Emission Deduction (E), Equivalent Bid $(\mathrm{Q})$, Penalty $(\mathrm{Pe})$ and Payment $(\mathrm{Pa})$. Their details and calculations are described in the following subsections.

\subsection{Construction Bid (C)}

In the conventional bidding method, bidders prepare their own bid prices according to the bill of quantity (BOQ) of the project. The Construction Bid (C) represents these bid prices, which should cover all their expenses and preferred markups. In advance, the owner's estimated cost (OC) is also prepared by the project owner. The OC is normally set as the owner's budget and formally announced to all bidders. In the CEP, the $\mathrm{OC}$ and $\mathrm{C}$ are used as references but the lowest $\mathrm{C}$ is not the winning criterion. A bidder who does not offer the lowest $\mathrm{C}$ can still be awarded the contract.

\subsection{Emission Deduction (E)}

The Emission Deduction (E) is a value in monetary terminology which is equal to an amount of GHG emission reduction (in kilogram unit of gas mass) multiplied with the unit eco-cost (proposed by Vogtländer [7]). The GHG reduction amount is determined by the options adopted by the bidder. Several approaches have a potential to reduce the emissions in road construction projects but the reduction options initially proposed for the CEP should suit the current capabilities of the participants and be easy enough to implement. However, these proposed reduction options can be gradually revised. As a result, the CEP method introduces six appropriate options for GHG emission reduction which are gathered from many sources such as recommendations of environmental agencies [33, 18, 34], guidance documents from machinery manufacturers [30-34], informative documents of retrofit devices [40, 18, 41], and previous research studies [42-44]. These six reduction options are grouped into three categories: the fuel technology is Option 1, the field management constitutes Options 2 and 3, and the engine technology includes Options 4, 5, and 6. These options are not compulsory but rather voluntary. Bidders who propose more options together with their submitted bids can increase this $\mathrm{E}$ value. Different bidders may prefer or be ready to implement different options on their submissions.

For each option, the amount of GHG emission is calculated based on the LCA process method. This is basically a multiplication of the overall energy, machinery and materials consumption by their emission factors (EF). These consumption amounts are calculated by assuming that the conventional and polluting construction method is used. For example, Option 1 is the total petroleum diesel consumption derived from the work hours and horsepower of the machinery; Option 2 is the total amount of hauling materials and recommended hauling distances as the input data, etc. After that, an amount of the emission reduction is also calculated. This varies depending on the particular factors of each option, such as the blend formula of biodiesel for Option 1 and the hauling distances saved from what are recommended for Option 2, etc. Eventually, these amounts of emission reductions are converted into monetary terms. All consumption parameters have to substitute into equations for $\mathrm{E}$ calculation. However, the direct calculation of $\mathrm{E}$ is quite complicated; hence, the CEP method provides a use of the relative coefficient for convenient purpose. The relative coefficient which is denoted as $\left(\alpha_{i}\right)$ is particularly prepared for each reduction option $i$. It is expressed in terms of a percentage of the OC of the current project. The E value is calculated by the following Eq. (2). 


$$
E=\sum_{i=1}^{6} \alpha_{i} \times O C
$$

where $\quad \alpha=$ the relative coefficient of the option

$\mathrm{i}=$ the $\mathrm{i}$ th. reduction options

$\mathrm{OC}=$ the owner's estimated costs.

In addition, a simplified version of $\alpha_{i}$ is also determined which is called the representative coefficient of the option $\mathrm{i}\left(\alpha_{\mathrm{Ri}}\right)$. This representative coefficient is aimed to facilitate the calculation of $\mathrm{E}$ on the bid date or it can be spared as an alternative calculation method. The $\alpha_{i}$ variable in Eq. (2) can be simplified to $\alpha_{\mathrm{Ri}}$ when an estimator would like to calculate an $\mathrm{E}$ by a representative coefficient. To demonstrate this concept, our research initiates this representative coefficient which is an average of $\alpha_{i}$ of three past projects selected as the base and representative projects. These three projects are just to demonstrate the concept. The number and the variety of these representative projects should be increased to generalize the result when being implemented. All the relevant data of these three base projects were collected and their values of GHG reduction have been thoroughly calculated beforehand. Then, the average value of the $\alpha_{\mathrm{i}}$ were used to derive the calculation equations for the representative coefficients. The representative coefficient $\left(\alpha_{\mathrm{Ri}}\right)$ is used to approximate the relative coefficient $\left(\alpha_{i}\right)$ by reducing some variables required in the formula. The details of the formula of the relative coefficient $\left(\alpha_{i}\right)$ and the representative coefficient $\left(\alpha_{R i}\right)$ for the six reduction options are described as follows.

\subsubsection{Option 1 - Use of biodiesel}

It is known that biodiesel consumption pollutes the environment less than petroleum diesel. However, this depends upon the blend formula of the biodiesel. The more the proportion of biodiesel in the blend formula is, the more the emission reduction is. Besides, the availability of the blends varies among different countries, for example, B5, B10 and B20 are sold in the U.S., but only B3 is sold in Mexico, and only B5 is available in Thailand. To deal with these limitations, the $\mathrm{E}_{1}$ calculation is described by Eq. (3) and some values are substituted in Eq. (4). This equation is based on the information on biodiesel emissions by EPA [45]. It relies on the percentage of biodiesel in the blend formulas. Likewise, it has already compensated for the consumption rate due to the lower heat energy of biodiesel. A markup is added as recommended by EPA [45]. Equation (4) has been normalized to Eq. (5) which is less complex.

$$
\begin{gathered}
\mathrm{E}_{1}=(\text { diesel_consumption }- \text { biodiesel_consumption }) \times \mathrm{EF} \times \text { horsepower } \\
\times \text { work_hour } \times \text { unit_eco-cost }
\end{gathered}
$$

where $\eta=$ coefficients for basic emission correlations $-\mathrm{NOx}=0.0009794, \mathrm{HC}=-0.011195, \mathrm{PM}=-$ 0.006384 and $\mathrm{CO}=-0.006561$

$\mathrm{a}=$ the percentage of biodiesel in the blend formulas from B1 to B20

$\mathrm{EF}=$ emission factor of diesel engine in Tier $1-\mathrm{NOx}=9.2, \mathrm{HC}=1.3, \mathrm{PM}=0.8, \mathrm{CO}=5.5$ $(\mathrm{g} / \mathrm{kWh})$

$\mathrm{hp}=$ horsepower of machinery (hp.)

$\mathrm{h}=$ work hours of machinery (hr.)

$\mathrm{p}=$ eco-cost of GHGs - NOx $=0.687, \mathrm{HC}=4.602, \mathrm{PM}=35.672$, and $\mathrm{CO}=0.312(\mathrm{USD} / \mathrm{kg})$ 
$\alpha_{1}=$ the relative coefficient of the reduction Option 1 (expressed in a percentage of OC)

$\mathrm{OC}=$ the owner's estimated project cost (in USD, U.S. dollars)

Equation (5) can be further simplified by substituting the values of $\mathrm{EF}, \mathrm{hp}, \mathrm{h}$ and $\mathrm{OC}$ of the three base projects. These information were collected by each project owner representative. The substitution is carried out each project. Three value of $\alpha_{\mathrm{i}}$ from Eq. (5) were calculated to an average relative coefficient or called representative coefficient $\left(\alpha_{\mathrm{Ri}}\right)$. The average value gives the result of the representative coefficient as shown in Eq. (6). In the case of the highest blend B20 ( $=20)$, the maximum $\alpha_{\mathrm{R} 1}$ is equal to $0.115 \%$.

\subsubsection{Option 2 - Material sources location}

Road construction requires a huge amount of raw materials, mostly including soil aggregates and crushed rocks, which are hauled to the construction site. Normally, the DOH recommends the location of material sources for a project but in practice the contractor always selects a different location. The locations of materials sources can impact the level of GHG emission [46]. The different distances between the recommended and the selected locations to the construction site are determined to calculate the emission reduction. The $E_{2}$ calculation is described by Eq. (7) and substituted later. Similarly, the relative coefficient $\left(\alpha_{2}\right)$ and the representative coefficient $\left(\alpha_{\mathrm{R} 2}\right)$ of this Option 2 are proposed in Eq. (8) and (9), respectively.

$$
\begin{aligned}
& \mathrm{E}_{2}=(\text { recommended_distance }- \text { practical_distance }) \times \mathrm{EF} \times \text { consumption_per_trip } \\
& \times \text { unit_eco-cost } \\
& \alpha_{2}=\frac{(\mathrm{R} D-O D) \times 2.711 \times F C \times T \times p}{O C} \times 100 \% \\
& \alpha_{\mathrm{R} 2}=0.0158 \times(b)-0.0997
\end{aligned}
$$

where $\alpha_{2}=$ the relative coefficient of the reduction Option 2 (expressed in a percentage of OC)

$\alpha_{\mathrm{R} 2}=$ the representative coefficient; $\mathrm{FC}=$ fuel consumption per hauling trip (given that the fuel consumption of a truck $=0.245 \mathrm{~L} / \mathrm{km}$ )

$\mathrm{RD}=$ the recommended hauling distance $(\mathrm{km})$

$\mathrm{OD}=$ the practical hauling distance $(\mathrm{km})$

$\mathrm{p}=$ eco-cost of $\mathrm{GHGs}-\mathrm{CO}_{2} \mathrm{eq}=0.176(\mathrm{USD} / \mathrm{kg})$

$\mathrm{T}=$ number of hauling trips

$\mathrm{b}=$ the saving hauling distance $(\mathrm{km})$ (or RD - OD).

Equation (8) shows that the $\alpha_{2}$ is derived from the emission rate of diesel at $2.711 \mathrm{kgCO} \mathrm{eq}_{2} / \mathrm{L}$ (as recommended by IPCC [47]), the different hauling distance, and the fuel consumption of the hauling trucks. Equation (9) is a simplified form of Eq. (8) when the three base projects are used as representatives. If the practical hauling distance is shorter than the $\mathrm{DOH}$ recommended (or the saving hauling distance (b)) in a range of 10 to 50 kilometers, the value of $\alpha_{\mathrm{R} 2}$ varies from 0.058 to $0.689 \%$.

\subsubsection{Option 3 - Construction techniques}

The use of alternative construction techniques is another option that can reduce the negative environmental impacts. According to the $\mathrm{DOH}$, three different construction techniques are approved for the base course work, namely soil-cement base mixed in-plant (SCB In-Plant), soil-cement base mixed in-place (SCB In-Place) and crushed rock base (CRB). These techniques, however, cause different GHG emission rates per cubic meter of materials [21] and the SCB-In-Plant produces the highest rate. The emission rates of CRB, SCB InPlace, and In-Plant from a previous research study by the authors is equal to $29.796,50.338$ and 59.997 $\mathrm{kg} / \mathrm{CO}_{2}$ eq, respectively [21]. If SCB In-Plant is set as a base of comparison, the emission reductions of these techniques are in relative percentages of $0 \%, 16.1 \%$ and $50.3 \%$ for SCB In-Plant, SCB In-Place and CRB, respectively. The description of the $\mathrm{E}_{3}$ calculation is presented in Eq. (10). These percentages are represented by the variable TEC as shown in Eq. (11). When simplifying the equation by the data from the three base projects, the $\alpha_{\mathrm{R} 3}$ in percentages is equal to $0 \%, 0.886 \%$ and $2.768 \%$ for SCB-In-Plant, SCB In-Place and CRB, respectively, as shown in Eq. (12). 


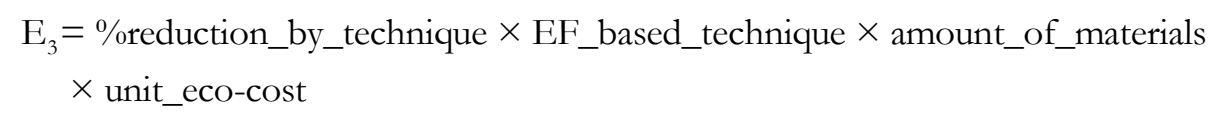

$$
\begin{gathered}
\alpha_{3}=\frac{T E C \times E R_{B} \times M \times p}{O C} \times 100 \% \\
\alpha_{\text {R3 }}=\left\{\begin{aligned}
0 \%, & S C B \text { In-Plant } \\
0.886 \%, & S C B \text { In-Place } \\
2.768 \%, & C R B
\end{aligned}\right.
\end{gathered}
$$

where $\alpha_{3}=$ the relative coefficient of the reduction Option 3 (expressed in a percentage of OC)

$\alpha_{\mathrm{R} 3}=$ the representative coefficient

TEC $=$ the relative percentages of emission reduction of the construction technique $(0 \%, 16.1 \%$, $50.3 \%)$

$\mathrm{ERB}=$ the base emission rate of the SCB In-Plant technique which is equal to $59.997 \mathrm{kgCO} 2 \mathrm{eq} / \mathrm{m}^{3}$ $\mathrm{M}=$ quantities of base course materials $\left(\mathrm{m}^{3}\right)$

$\mathrm{p}=$ eco-cost of $\mathrm{GHGs}-\mathrm{CO}_{2} \mathrm{eq}=0.176(\mathrm{USD} / \mathrm{kg})$.

\subsubsection{Option $4-$ Newer machinery replacement}

A newer model of machinery is more environmentally friendly than an older one. According to EPA [18], diesel-based heavy machinery is classified into five tiers, namely Tier 1, 2, 3, 4i and 4f, which have different effects on GHG emission. Tier 1 machinery is considered the oldest and emits the highest level of GHG. Table 1 shows the percentages of GHG emission reduction based on the emission rate of the Tier 1 machinery where the machinery in a size range of $100-175 \mathrm{hp}$. is considered [18].

The list of machinery usage proposed by bidders shows the proportion of machines of different tiers together with their horsepower and working hours. The more the quantity and the newer the model of machinery proposed the greater the increase in the emission reduction will be. The bidders can achieve a higher emission reduction if they replace their old machines with newer machinery of a higher tier. To determine the emission reductions, the bidders have to propose a list of heavy construction machinery that will be used in the project. Therefore, a generated form of the $\mathrm{E}_{4}$ calculation is presented in Eq. (13) and Eq. (14) which is used to calculate the relative coefficient of this option. While Eq. (15) is a simplified form where the machinery details of the three base projects (the replacement of Tier 1 by Tier 2, 3, $4 \mathrm{i}$ and $4 \mathrm{f}$ is assumed to be $20 \%$ equally) are used as representatives.

$$
\begin{aligned}
\mathrm{E}_{4} & =\sum_{\mathrm{n}=\text { tier1 }}^{\text {tier4f }}\left(\sum_{\text {each_gas }} \% \text { oreduction_by_tier } \times \text { horsepower } \times \text { work_hour } \times \text { unit_eco-cost }\right) \\
& \times \% \text { newer_replacement }
\end{aligned}
$$

$$
\begin{gathered}
\alpha_{4}=\frac{\sum_{n=\text { tier } 1}^{\text {tier } 4}\left(\sum_{m=I}^{I V} R_{m} \times h p \times h \times p\right) \times r_{n}}{O C} \times 100 \% \\
\alpha_{R 4}=\sum_{n=\text { tier } 1}^{\text {tier } 4 f}\left(\alpha_{a 4} \times r_{n}\right)
\end{gathered}
$$

where $\alpha_{4}=$ the relative coefficient of the reduction Option 4 (expressed in a percentage of OC)

$\alpha_{\mathrm{R} 4}=$ the representative coefficient

$\mathrm{R}_{\mathrm{rn}}=$ rate of emission reduction (NOx, HC, PM and CO) by Option 4 (see Table 1)

$\mathrm{hp}=$ horsepower of machinery (hp.)

$\mathrm{h}=$ work hours of machinery (hr.) 
$\mathrm{p}=$ eco-cost of $\mathrm{GHGs}-\mathrm{NOx}=0.687, \mathrm{HC}=4.602, \mathrm{PM}=35.672$ and $\mathrm{CO}=0.312(\mathrm{USD} / \mathrm{kg})$

$r_{n}=$ the percentage of machinery replacement (newer model than Tier 1 ) between $0 \%$ to $100 \%$

$\alpha_{24}=$ the average of representative emission deductions by Option 4 (given that Tier $1=0$, Tier $2=$ 0.215 , Tier $3=0.255$, Tier $4 \mathrm{i}=0.406$ and Tier $4 \mathrm{f}=0.436$ ).

Table 1. Rates of emission reduction in case of newer machinery replacement $\left(\mathrm{R}_{\mathrm{rn}}\right)$.

\begin{tabular}{ccccc}
\hline $\begin{array}{c}\text { GHGs } \\
\text { reduction }\end{array}$ & $\begin{array}{c}\text { NOx } \\
(\mathbf{I})\end{array}$ & $\begin{array}{c}\text { HC } \\
(\text { II) }\end{array}$ & $\begin{array}{c}\text { PM } \\
(\text { III) }\end{array}$ & $\begin{array}{c}\text { CO } \\
\text { (IV) }\end{array}$ \\
\hline Tier 1 & - & - & - & - \\
Tier 2 & - & - & $62.5 \%$ & $9.1 \%$ \\
Tier 3 & $62.0 \%$ & - & $62.5 \%$ & $9.1 \%$ \\
Tier 4i & $62.0 \%$ & $69.2 \%$ & $97.5 \%$ & $9.1 \%$ \\
Tier 4f & $95.7 \%$ & $85.4 \%$ & $97.5 \%$ & $9.1 \%$ \\
\hline
\end{tabular}

3.2.5. Option 5 - Hybrid machinery replacement

A hybrid machinery model has resulted in low emissions and high energy efficiency. According to some wellknown manufacturers [35-37, 39], the hybrid systems can reduce emissions more than the Tier $4 \mathrm{f}$ diesel based engines, for example, by 15\%-30\% for Hitachi, by 5\%-41\% for Komatsu, by $25 \%-33 \%$ for Caterpillar, and by $10 \%$ for Volvo. With regard to this information, it is reasonable to set the $10 \%$ reduction conservatively on top of the percentage reduction of the Tier $4 \mathrm{f}$ machinery. Table 2 shows the results of the combined reduction rates in percentages for different GHGs $[35,37,39]$. As for the evaluation process, the bidders have to propose a list of heavy construction machinery that implements the hybrid technology. The hybrid machinery usage is proposed in terms of a percentage of the whole machinery fleet. The $\mathrm{E}_{5}$ calculation is presented in Eq. (16). Meanwhile, Eq. (17) is the calculation of the relative coefficient and Eq. (18) is a simplified form. The maximum range of $\alpha_{\mathrm{R} 5}$ is equal to $0.451 \%$, when all the machinery is substituted for the hybrid model.

$$
\begin{gathered}
\mathrm{E}_{5}=\left(\sum_{\text {each_gas }} \% \text { oreduction_hybrid } \times \text { horsepower } \times \text { work_hour } \times \text { unit_eco-cost }\right) \\
\times \% \text { hybrid_usage } \\
\alpha_{5}=\frac{\left(\sum_{r b=I}^{I V} R_{r b} \times h p \times h \times p\right) \times r_{b}}{O C} \times 100 \% \\
\alpha_{R 5}=0.451 \times r_{b}
\end{gathered}
$$

where $\alpha_{5}=$ the relative coefficient of the reduction Option 5

$\alpha_{\mathrm{R} 5}=$ the representative coefficient

$\mathrm{hp}=$ horsepower of machinery (hp.)

$\mathrm{h}=$ work hours of machinery

$\mathrm{p}=$ eco-cost of GHGs

$\mathrm{R}_{\mathrm{rh}}=$ rate of emission reduction (NOx, HC, PM, and CO) by Option 5 (see Table 2)

$\mathrm{r}_{\mathrm{h}}=$ the percentage of hybrid model machinery usage between $0 \%$ to $100 \%$. 
Table 2. Rates of emission reduction in case of hybrid machinery replacement $\left(\mathrm{R}_{\mathrm{rh}}\right)$.

\begin{tabular}{ccccc}
\hline $\begin{array}{c}\text { GHGs } \\
\text { reduction }\end{array}$ & $\begin{array}{c}\text { NOx } \\
(\mathrm{I})\end{array}$ & $\begin{array}{c}\text { HC } \\
\text { (II) }\end{array}$ & $\begin{array}{c}\text { PM } \\
(\mathrm{III})\end{array}$ & $\begin{array}{c}\text { CO } \\
\text { (IV) }\end{array}$ \\
\hline Hybrid & $100 \%$ & $93.9 \%$ & $100 \%$ & $10.1 \%$ \\
\hline
\end{tabular}

3.2.6. Option 6 - Retrofit devices installation

An installation of a retrofit device mitigates the emissions. The installed retrofits are either comprised of a single or combined technology. The single technology includes a diesel particulate filter (DPF), a diesel oxidation catalyst (DOC) and a selective catalytic reduction (SCR). The combined technology is a coalition of two single technologies such as an SCR and a DPF and an exhaust gas recirculation (EGR) and a DPF. The emission reduction depends upon the percentage of installation of the retrofit devices of the total machinery. Informative documents concerning the retrofit devices have presented various effects on reducing the emissions $[18,40-42,44]$. A DOC device is able to reduce the emissions of NOx by $5 \%$, of CO by $70 \%-$ 95\%, of HC by $70 \%-90 \%$, and of PM by $85 \%-95 \%$ [40]. A DPF device is claimed to reduce the emissions of NOx by $5 \%$, of CO by $60 \%-90 \%$, of HC by $60 \%-90 \%$ and of PM by $85 \%-95 \%$. An SCR device can reduce the emissions of NOx by 70\%- $90 \%$, of CO by $50 \%-90 \%$, of HC by $50 \%-90 \%$ and of PM by $25 \%-50 \%$ [18]. Furthermore, combining devices such as an SCR+DPF device can reduce the emission of NOx by $70 \%$, of CO by $90 \%$, of HC by $90 \%$ and of PM by $90 \%$ [41]. An EGR+DPF device reduces NOx by $60 \%$, CO by $60 \%$, HC by $60 \%$, and PM by $90 \%$ [18]. This study considers the devices that are expected to provide more than a $50 \%$ reduction.

An assumption is set up to generate the $\mathrm{E}_{6}$ calculation in Eq. (19). At the same time, a reform contributes to the $\alpha_{6}$ calculation in Eq. (20) in which the machinery is substituted in Tier 3 first and the retrofit devices are installed, as listed in Table $3[18,40,42,44]$. This equation derives from the usage and the type of retrofit devices. The representative coefficient $\left(\alpha_{\mathrm{R} 6}\right)$ is in Eq. (21). Consequently, the installation of these retrofit devices have a maximum of $0.173 \%, 0.240 \%, 0.208 \%, 0.260 \%$, and $0.250 \%$ reduction when machinery is installed with a DOC, a DPF, an SCR, an SCR+DPF and an EGR+DPF by 100\%, respectively.

$$
\begin{aligned}
\mathrm{E}_{6}= & \left(\sum_{\text {each_gas }} \% \text { reduction_by_device } \times \text { horsepower } \times \text { work_hour } \times \text { unit_eco-cost }\right) \\
& \times \% \text { device_installation }
\end{aligned}
$$

$$
\begin{gathered}
\alpha_{6}=\frac{\left(\sum_{i d=I}^{I V} R_{i d} \times h p \times h \times p\right) \times i_{d}}{O C} \times 100 \% \\
\alpha_{\mathrm{R} 6}=\alpha_{a 6} \times i_{d}
\end{gathered}
$$

where $\alpha_{6}=$ the relative coefficient of the reduction Option 6

$\alpha_{\mathrm{R} 6}=$ the representative coefficient

$\mathrm{hp}=$ horsepower of machinery (hp.)

$\mathrm{h}=$ work hours of machinery

$\mathrm{p}=$ eco-cost of GHGs

$\mathrm{R}_{\mathrm{id}}=$ rate of emission reduction (NOx, HC, PM and CO) by Option 6 (see Table 3)

$i_{d}=$ the percentage of a retrofit device installation - DOC, DPF, SCR, SCR+DPF and EGR+DPF

- between $0 \%$ to $100 \%$

$\alpha_{a 6}=$ the average of representative emission deductions by Option 6 . 
Table 3. Rates of emission reduction in case of retrofit devices installation $\left(\mathrm{R}_{\mathrm{id}}\right)$.

\begin{tabular}{lcccc}
\hline \multicolumn{1}{c}{ GHGs reduction } & $\begin{array}{c}\text { NOx } \\
(\mathrm{I})\end{array}$ & $\begin{array}{c}\text { HC } \\
(\mathrm{II})\end{array}$ & $\begin{array}{c}\text { PM } \\
(\mathrm{III})\end{array}$ & $\begin{array}{c}\text { CO } \\
(\mathrm{IV})\end{array}$ \\
\hline Tier 3+DOC & $62 \%$ & - & $68.75 \%$ & $15.47 \%$ \\
Tier 3+DPF & $62 \%$ & - & $100 \%$ & $14.56 \%$ \\
Tier 3+SCR & $100 \%$ & - & $78.13 \%$ & $13.65 \%$ \\
Tier 3+SCR+DPF & $100 \%$ & - & $100 \%$ & $17.29 \%$ \\
Tier 3+EGR+DPF & $99.2 \%$ & - & $100 \%$ & $14.56 \%$ \\
\hline
\end{tabular}

In addition, Table 4 shows the maximum range of the representative coefficient of these six reduction options when each of them is fully and individually implemented. These coefficients vary from $0.115 \%$ to $2.768 \%$. Some options can be implemented together, whereas the others are mutually exclusive such as Option 4, 5 and 6. All possible combinations of these six reduction options are investigated. There are thirtyone possible combinations that a bidder can adopt, given that each option is fully implemented at its maximum value of $\alpha_{\mathrm{Ri}}$. In the case of a single-option adoption, Table 4 shows the maximum values of the representative coefficients of the six options. The maximum representative coefficient for a single-option adoption is in Option 3 which is equal to $2.768 \%$. However, in the case of a two-option adoption, the combination of Option $2+3$ results in a maximum representative coefficient of $3.457 \%$. A three-option adoption of Option $2+3+5$ gives a maximum of $3.908 \%$. Lastly, a four-option adoption of Option $1+2+3+5$ gives a maximum value of $4.023 \%$.

Table 4. The maximum values of representative coefficients of the six options.

\begin{tabular}{ccccccc}
\hline Option & 1 & 2 & 3 & 4 & 5 & 6 \\
\hline$\alpha_{\mathrm{Ri}}$ & $0.115 \%$ & $0.689 \%$ & $2.768 \%$ & $0.436 \%$ & $0.451 \%$ & $0.260 \%$ \\
\hline
\end{tabular}

\subsection{Equivalent Bid (Q)}

An Equivalent Bid (Q) is an amount which is considered in the bid evaluation. It is simply calculated by deducting $\mathrm{E}$ from $\mathrm{C}$ as shown in Eq. (22). The CEP bidding method employs the lowest $\mathrm{Q}$ as a criterion for winning instead of the lowest $\mathrm{C}$ in the conventional bidding method. A bidder who submits the lowest $\mathrm{Q}$ is the winner.

$$
Q=C-E
$$

where $\mathrm{Q}=$ equivalent bid

$\mathrm{C}=$ construction bid

$\mathrm{E}=$ emission deduction.

\subsection{Penalty (Pe)}

In order to ensure the integrity of the CEP method, a punishment measure must be incorporated and well enforced. The CEP method defines the punishment and includes it as a part of the contract. The punishment is adopted on a concept of the incentive/disincentive contract. The punishment should be fair to the next lowest bidder who loses the competition. The winning bidder (now a contractor) who fails to fulfill all their proposed options of the emission reduction will be considered to breach the contract agreements and be penalized. This contractor tends to actually produce more emissions than stated in the proposal so that their Emission Deduction (E) should be revised and reduced. Therefore, all field operations throughout the project, especially the ones related to the GHG emissions, need to be monitored by the owner's representatives or the inspectors. Materials, machinery and fuel consumptions on the site are mandatorily reported. The monitoring is necessary in order to examine the actual emission reduction. The actual equivalent bid $\left(\mathrm{Q}^{\prime}{ }_{\mathrm{wb}}\right)$ 
of the winner (now the contractor), which should be higher than the winning equivalent bid $\left(\mathrm{Q}_{\mathrm{wb}}\right)$, is calculated.

A financial penalty $(\mathrm{Pe})$ is particularly used as the punishment. The amount of the penalty depends on the actual emission reduction that has to be quantified during the construction phase. The equivalent bid of the next lowest bidder $\left(\mathrm{Q}_{\mathrm{nlb}}\right)$, who could be the winner, is also used as a reference for the penalty calculation. The penalty is defined in two cases. In the first case, the penalty type-1 (Pe1) is applied when $\mathrm{Q}^{\prime}{ }_{\mathrm{wb}}$ does not exceed $\mathrm{Q}_{\mathrm{nlb}}$. Pe1 is equal to the difference between $\mathrm{Q}_{\mathrm{wb}}^{\prime}$ and $\mathrm{Q}_{\mathrm{wb}}$. Although the contractor partly fails to reduce the emission through the proposed options, the amount of difference is trivial and it would not change the bid result. In another case, the penalty type-2 (Pe2) is applied when $\mathrm{Q}_{\text {wb }}$ is greater than $\mathrm{Q}_{\mathrm{nlb}}$, if the contractors cannot implement the reduction options on offer. This contractor's failure is significant enough to prevent the next lowest bidder from being the true winner. The Pe2 amount should not include only the difference between the $\mathrm{Q}_{\mathrm{n}}$ and the $\mathrm{Q}_{\mathrm{wb}}$ but should also add a surplus of 5\% on top. The penalty is shown in Eq. (23).

$$
P e=\left\{\begin{array}{l}
P e 1=Q_{w b}^{\prime}-Q_{w b}, \quad Q_{w b}^{\prime} \leq Q_{n l b} \\
P e 2=\left(Q_{n l b}-Q_{w b}\right)+\left[\left(Q_{w b}^{\prime}-Q_{n l b}\right) \times(1+5 \%)\right], \quad Q_{w b}^{\prime}>Q_{n l b}
\end{array}\right.
$$

where $\mathrm{Pe}=$ financial penalty (USD)

Qwb = equivalent bid of winning bidder (USD)

$\mathrm{Q}_{\mathrm{nlb}}=$ equivalent bid of next lowest bidder (USD)

$\mathrm{Q}_{\mathrm{wb}}^{\prime}=$ actual equivalent bid of winning bidder (USD).

As a result of having signed a written agreement, the punishment measure can be applied to those who fail to abide by the agreement (or contract).

\subsection{Payment $(\mathbf{P a})$}

The payment is the total amount of money, which the project owner gradually pays to the contractor toward the project completion. The contractor will receive the maximum payment equal to $C$ if they can achieve all emission reductions as proposed. In this case, there is no punishment. However, the contractor who fails to abide by the agreement will receive less payment from the owner and consequently, the punishment will be enforced. The penalty could be taken from a letter of bank guarantee, which must be provided on the date of signing the contract and should be enough to cover the maximum penalty. The payment $(\mathrm{Pa})$ is simply calculated by the following Eq. (24).

$$
P a=C-P e
$$

where $\mathrm{Pa}=$ the total amount of payment received by the contractor

$\mathrm{C}=$ construction bid

$\mathrm{Pe}=$ penalty.

\section{Practical Application}

To illustrate the application of the CEP method, some case studies have been selected from historical public road construction projects for simulations of the CEP scheme. The first analysis is targeted on the price gaps between the lowest bid (LB) and the next lowest bid (NLB) on fourteen projects. All of these projects were owned by the Department of Highways of Thailand (DOH) and were awarded during the years 2014 to 2016. A traditional criterion for evaluating these bids was to consider the lowest bid price (or term C only). Table 5 shows the different numbers of participating bidders, the winning bid prices and the associated percentages of the price gaps in these biddings. 
Table 5. Price gaps between LB and NLB of the fourteen case studies.

\begin{tabular}{cccc}
\hline Project & $\begin{array}{c}\text { Participant } \\
\text { bidders }\end{array}$ & $\begin{array}{c}\text { Bid price of winning } \\
\text { bidder (million USD) }\end{array}$ & $\begin{array}{c}\text { \% of Gap between } \\
\text { LB and NLB }\end{array}$ \\
\hline $2014 \# 1$ & 8 & 16.93 & $0.52 \%$ \\
$2014 \# 2$ & 7 & 22.53 & $0.21 \%$ \\
$2015 \# 1$ & 5 & 13.79 & $9.03 \%$ \\
$2015 \# 2$ & 9 & 13.08 & $7.75 \%$ \\
$2015 \# 3$ & 10 & 9.80 & $3.66 \%$ \\
$2015 \# 4$ & 7 & 9.06 & $2.48 \%$ \\
$2015 \# 5$ & 12 & 8.38 & $1.61 \%$ \\
$2016 \# 1$ & 15 & 4.97 & $2.45 \%$ \\
$2016 \# 2$ & 9 & 7.40 & $0.04 \%$ \\
$2016 \# 3$ & 5 & 10.22 & $9.92 \%$ \\
$2016 \# 4$ & 3 & 18.20 & $0.22 \%$ \\
$2016 \# 5$ & 2 & 18.42 & $0.09 \%$ \\
$2016 \# 6$ & 2 & 33.39 & $0.19 \%$ \\
$2016 \# 7$ & 4 & 30.87 & $3.11 \%$ \\
\hline Average & 7 & 15.50 & $2.95 \%$ \\
\hline
\end{tabular}

The results show that the gaps can vary dramatically from $0.04 \%$ to $9.92 \%$ with an average gap of about $2.95 \%$. In most projects (9 of 14), the gaps are less than the average and in half of all the projects, the gaps are even less than 1\%. This indicates that the Emission Deduction (E) for the Equivalent Bid (Q) could possibly change the winners of these biddings. To demonstrate this circumstance, two projects, i.e. 2014\#1 and $2016 \# 3$ were chosen for a further simulation.

The simulation assumes that the two biddings are under the CEP scheme. In the bidding phase, all bidders still submit their own bid prices or Cs. Furthermore, all bidders except the lowest $\mathrm{C}$ ones submit their proposed Es together with their Cs. The details of the actual bid prices, which are considered as term $\mathrm{C}$ of the CEP, are shown in Table 6 . Moreover, Table 6 shows simulated events which most bidders have proposed for their reduction options (considered as term E). The Equivalent Bids (Q) are calculated accordingly.

In the case of Project 2014\#1, the result of the simulation indicated that Bidder $\mathrm{H}$ might have won the competition because they submitted the lowest $\mathrm{Q}$. The bid result possibly changes, although Bidder H did not submit the lowest $\mathrm{C}$ but the highest $\mathrm{C}$. This simulated case shows that the term $\mathrm{E}$ has much potential to make a bidder overcomes the other bidders. In this case, although Bidder $\mathrm{H}$ submitted the highest $\mathrm{C}$ and the highest E, they still won the competition because of the lowest Q.

However, the results of the other Project (2016\#3) reveal that the winner was still Bidder I, even though Bidders J, K, L and M submitted their Es as high as possible in the competition. This can be explained by the fact that Bidder I submitted a very low $\mathrm{C}$ and produced a large price gap between LB and NLB i.e. $9.92 \%$, which is beyond the effective range of the deduction E. Hence, the price gap was greater than $4 \%$, so the eco-cost term should be applied with a higher weighting factor. In this hypothetical case of Project 2016\#3, if five as a weighting factor was applied to the term E under the CEP scheme, Bidder J would become the winner.

Another simulation based on Project 2014\#1 is cited to demonstrate the punishment clause of the CEP. The punishment measure as a penalty will be applied to the contractor who fails to fulfill the contract. In this case, Bidder $\mathrm{H}$ is the awarded contractor with the equivalent bid $\left(\mathrm{Q}_{\mathrm{wb}}\right)$ of USD 16.66 million, and Bidder $\mathrm{G}$ is the next lowest bidder with the equivalent bid $\left(\mathrm{Q}_{\mathrm{nlb}}\right)$ of USD 16.68 million. If it is assumed that Bidder $\mathrm{H}$ performs poorly and violates the contract. Then their actual emission reduction will be lower than their proposed rates. Thus the financial penalty will be applied as follows: in the case of the $\mathrm{Q}^{\prime}{ }_{\mathrm{wb}}$ which is calculated based on the field monitoring data equal to USD 16.67 million, the penalty type-1 (Pe1), equal to (16.6716.66) = USD 0.01 million, will be applied. However, if the contractor performs even worse, and their $\mathrm{Q}^{\prime}{ }_{\mathrm{wb}}$ 
increases to USD 17.09 million, the penalty type-2 (Pe2) will be then applied. This penalty will increase to $(16.68-16.66)+[(17.09-16.68) \times 1.05]=$ USD 0.45 million. Figure 1 illustrates these simulated penalty calculations.

Table 6. Details of bid prices of the case studies of projects 2014\#1 and 2016\#3.

\begin{tabular}{|c|c|c|c|c|c|c|c|c|c|c|}
\hline & \multirow{2}{*}{$\begin{array}{l}\text { Construction } \\
\text { Bid (C) }\end{array}$} & \multirow{2}{*}{$\begin{array}{l}\text { Prices } \\
\text { Gap }\end{array}$} & \multicolumn{7}{|c|}{ Emission Deduction (E) } & \multirow{2}{*}{$\begin{array}{c}\text { Equivalen } \\
\text { Bid (Q) }\end{array}$} \\
\hline & & & $\mathrm{E}_{1}$ & $\mathrm{E}_{2}$ & $\mathrm{E}_{3}$ & $\mathrm{E}_{4}$ & $\mathrm{E}_{5}$ & $\mathrm{E}_{6}$ & $\mathrm{E}_{\text {Total }}$ & \\
\hline \multicolumn{11}{|c|}{ Case of $2014 \# 1(\mathrm{OC}=17.19)$} \\
\hline Bidder A & 16.93 & - & - & - & - & - & - & - & - & 16.93 \\
\hline Bidder B & 17.02 & 0.09 & - & 0.12 & - & - & - & - & 0.12 & 16.90 \\
\hline Bidder C & 17.12 & 0.19 & - & 0.12 & - & - & 0.08 & - & 0.20 & 16.92 \\
\hline Bidder D & 17.13 & 0.20 & 0.03 & 0.12 & - & 0.08 & - & - & 0.23 & 16.90 \\
\hline Bidder E & 17.14 & 0.21 & 0.03 & 0.12 & - & 0.08 & - & - & 0.23 & 16.91 \\
\hline Bidder F & 17.15 & 0.22 & 0.03 & 0.12 & - & - & 0.08 & - & 0.23 & 16.92 \\
\hline Bidder G & 17.16 & 0.23 & - & - & 0.48 & - & - & - & 0.48 & 16.68 \\
\hline Bidder $\mathrm{H}$ & 17.17 & 0.24 & 0.03 & - & 0.48 & - & - & - & 0.51 & 16.66 \\
\hline \multicolumn{11}{|c|}{ Case of $2016 \# 3(\mathrm{OC}=15.05)$} \\
\hline Bidder I & 10.22 & - & - & - & - & - & - & - & - & 10.22 \\
\hline Bidder J & 11.23 & 0.96 & 0.02 & 0.10 & 0.42 & - & 0.07 & - & 0.61 & 10.62 \\
\hline Bidder K & 12.77 & 1.11 & 0.02 & 0.10 & 0.42 & - & 0.07 & - & 0.61 & 12.16 \\
\hline Bidder L & 12.79 & 1.11 & 0.02 & 0.10 & 0.42 & 0.07 & - & - & 0.61 & 12.18 \\
\hline $\begin{array}{c}\text { Bidder } \\
\mathrm{M}\end{array}$ & 14.06 & 1.75 & 0.02 & 0.10 & 0.42 & - & - & 0.04 & 0.58 & 13.48 \\
\hline
\end{tabular}

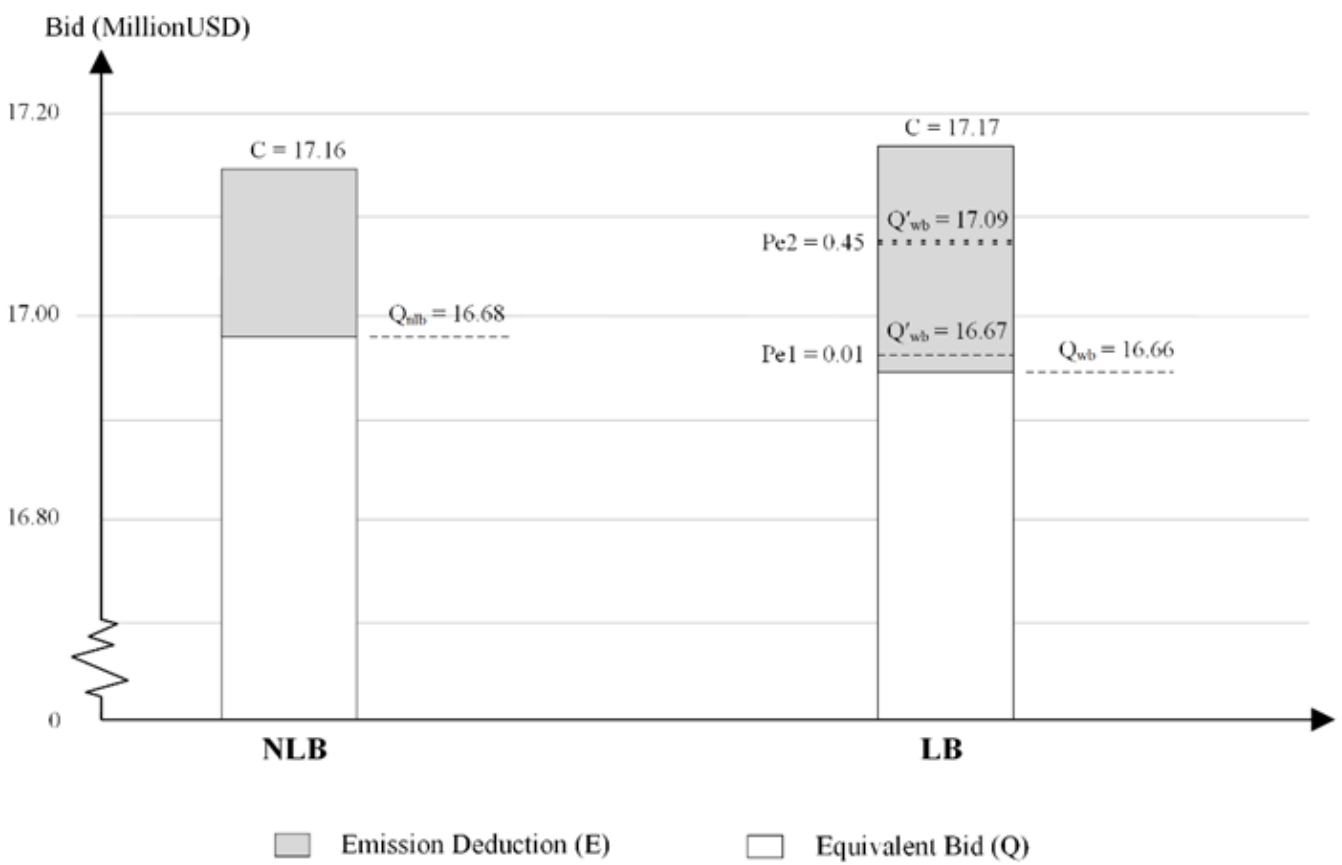

Fig. 1. Simulated punishment in the case study of project. 


\section{Conclusion}

In this study, the Construction-Emission-Punishment (CEP) bidding method is proposed as a means for reducing GHG emissions in road construction projects. The CEP method is designed to offer an incentive scheme to the contractors who improve their equipment and decrease their current energy consumption in order to achieve higher energy efficiencies. The method is an effective measure to encourage more voluntary participation in GHG reductions. It consists of six steps which will be performed as a part of the contractual obligation. These modified procedures are created to adapt the bid evaluation criterion. More conditions are added to the conventional bidding procedure. They are represented in terms of Emission Deduction (E) in six reduction options and punishment by two types of financial penalties $(\mathrm{Pe})$.

Each of the six reduction options initiated in this research has its own different contribution to E. The option that can give a large E will increase the cost. For instance, Option 1, which uses biodiesel, does not incur extra cost due to a governmental subsidization and provides only a small E. However, Options 4 and 5 , which involve machinery replacement, increase the costs considerably but give a larger $\mathrm{E}$ in return. Although the replacement options seem expensive, they will be requited by other benefits i.e. work productivity improvement and efficient energy consumption of the contractors. However an emission reduction of $0.2 \%-2.8 \%$ of the project costs seems too low to influence decisions and impact policymaking, it justifies a fair threshold. In future, developed technologies would also provide a cheaper cost and a larger E. Then, this CEP will also be more effective bidding method.

The CEP method procedures can be achieved when it is performed by a suitable contract and procurement method. Any form of competitive bidding that can combine terms of construction cost and environmental cost will serve the purpose. A unit-price contract and a sealed bid auction are recommended for the procurement method as well as they are a conventional method for public construction projects. This CEP method has a potential to be adopted on both public and private construction projects. For the owners who are aware of the environmental issue, this CEP is an interesting alternative.

The simulations of the case study show that the CEP method could change the bidding result through the incentive measures. The price gap between the lowest $C$ and the next lowest $C$ is a key factor. The small price gap can attract more competitors using a compensation for the term E. According to the historical bid data on road construction projects in Thailand, this price gap is normally less than $1 \%$. In the case that the price gap is high, the weighting factor for the term E should be applied and its suitable value should be determined. The results from the case study reveals that the winning bidder could be changed under the CEP method if some reduction options were proposed to get enough $\mathrm{E}$.

Nonetheless, the CEP method has some limitations such as a suitable weighting factor of the term E. This depends on the norm of the bid competitions which indicates the range of the price gaps in the bid. The use of a simplified form of relative coefficients heavily relies on the selected base projects which are used to determine the representative coefficients. Besides, six reduction options are quite a few. They are just initial suggestions for this research. Any recommendations from relevant parties should be gathered after the CEP is implemented for a while so that these reduction options can be revised accordingly. Moreover, in order to maintain the justification of this method and to implement it successfully, field monitoring and the punishment scheme is required in the post-bidding phase.

\section{References}

[1] The Intergovernmental Panel on Climate Change (IPCC), "Fifth assessment report - synthesis report," Contribution of Working Groups I, II and III to the Fifth Assessment Report of the Intergovernmental Panel on Climate Change, Geneva, Switzerland, 2014.

[2] United Nations Framework Convention on Climate Change (UNFCC). (1998). Kyoto Protocol [Online]. Available: http://unfccc.int/kyoto_protocol/items/2830.php [Accessed: 16 Oct. 2015].

[3] United States Environmental Protection Agency (EPA), "Quantifying greenhouse gas emissions from key industrial sectors in the United States," Working Draft, U.S. EPA, Washington, DC, 2008.

[4] Union of Concerned Scientists (UCS). (2007). Findings of the IPCC Fourth Assessment Report: Climate Change Mitigation [Online]. Available: http://www.ucsusa.org/assets/documents/global_warming/IPCCWGIII-UCS-summary-72dpi.pdf [Accessed: 20 Nov. 2015].

[5] Office of National Environmental Policy and Planning (ONEP), "2nd Thailand's national GHG inventories report,” (in Thai) Ministry of Natural Resources and Environment, Bangkok, 2010. 
[6] K. Park, Y. Hwang, S. Seo, and H. Seo, "Quantitative assessment of environmental impacts on life cycle of highways," J. Constr. Eng. Manage., vol. 129, no. 1, pp. 25-31, 2003.

[7] United States Geological Survey (USGS), "Materials in use in U.S. interstate highways," Fact Sheet 2006-3127, U.S. Geological Survey, Denver, 2006.

[8] A. Eštoková and M. Porhinčák, "Reduction of primary energy and $\mathrm{CO}_{2}$ emissions through selection and environmental evaluation of building materials," Theor. Found. Chem. Eng., vol. 46, no. 6, pp. 704712, 2012.

[9] C. Ahn, F. Peña-Mora, S. Lee, and C. A. Arboleda, "Consideration of the environmental cost in construction contracting for public works: $\mathrm{A}+\mathrm{C}$ and $\mathrm{A}+\mathrm{B}+\mathrm{C}$ bidding methods," J. Manage. Eng., vol. 29, no. 1, pp. 86-94, 2013.

[10] H. G. Avetisyan, E. Miller-Hooks, and S. Melanta, "Decision models to support greenhouse gas emissions reduction from transportation construction projects," J. Constr. Eng. Manage., vol. 138, no. 5, pp. 631-641, 2012.

[11] D. Cass and A. Mukherjee, "Calculation of greenhouse gas emissions for highway construction operations by using a hybrid life-cycle assessment approach: case study for pavement operations," $J$. Constr. Eng. Manage., vol. 137, no. 11, pp. 1015-1025, 2011.

[12] N. Santero, A. Loijos, and J. Ochsendorf, "Greenhouse gas emissions reduction opportunities for concrete pavements," Int. J. of Ind. Eco., vol. 17, no. 6, pp. 859-868, 2013.

[13] D. Puri and S. Tiwari, "Evaluating the criteria for contractors' selection and bid evaluation," Int. J. of Eng. Sci. Inv., vol. 3, no. 7, pp. 44-48, 2014.

[14] J. A. Fava, "Why take a life cycle approach?," the United Nations Publication, Nairobi, Kenya, 2004.

[15] M. Finkbeiner, A. Inaba, R. Tan, K. Christiansen, and H.-J. Klüppel, "The new international standards for life cycle assessment: ISO 14040 and ISO 14044," Int. J. Life Cycle Assess., vol. 11, no. 2, pp. 80-85, 2006.

[16] T. Hong, C. Ji, M. Jang, and H. Park, "Assessment model for energy consumption and greenhouse gas emissions during building construction," J. Manage. Eng., vol. 30, no. 2, pp. 226-235, 2014.

[17] Society of Environmental Toxicology and Chemistry (SETAC), "Guidelines for social life cycle assessment of products," United Nations Publication, Nairobi, Kenya, 2009.

[18] United States Environmental Protection Agency (EPA), "National clean diesel campaign — Innovative Strategies for Cleaner Air - 2005 Progress Report,” EPA420-R-06-009, Office of Transportation and Air Quality, U.S. EPA, Washington, DC, 2005.

[19] Global Renewable Fuels Alliance (GRFA). (2016). Global Biofuel Mandates. Available: http://globalrfa.org/biofuels-map/ [Accessed: 18 Jan. 2016]

[20] United Nations Conference on Trade and Development (UNCTAD), "The state of the biofuels market: Regulatory, trade and development perspectives," Draft Advance Copy, UNCTAD/DITC/TED/2013/8, United Nations Publication, Geneva, Switzerland, 2014.

[21] M. Metham and V. Benjaoran, "Comparison greenhouse gas emissions due to different construction techniques on road construction project," (in Thai) Technical Education Journal King Mongkut's University of Technology North Bangkok, vol. 7, no. 2, pp. 1-9, 2016.

[22] Q. Cui, X. Zhu, L. Whitten, and R. Dason-Deane, "Innovative Contracting Strategies for Combating Climate Change - Maryland State Highway Administration - Final Report," MD-11-SP009B4G, University of Maryland, MD, 2011.

[23] A. X. Sanchez, L. Lehtiranta, K. D. Hampson, and R. Kenley, "Evaluation framework for green procurement in road construction," Smart and Sustainable Built Environment, vol. 3, no. 2, pp. 153-169, 2014.

[24] A. A. M. Bohari, M. Skitmore, B. Xia, and M. Teo, "Green oriented procurement for building projects: Preliminary findings from Malaysia," J. Clean. Prod., vol. 148, pp. 690-700, 2017.

[25] V. Annika, B. Berit, and C. Faith-Ell, "Environmental consideration in procurement of construction contracts: current practice, problems and opportunities in green procurement in the Swedish construction industry," J. Clean. Prod., vol. 17, no. 13, pp. 1214-1222, 2009.

[26] Q. Shi and Z. Chen, "Research on carbon problems in the construction industry," in Proceedings of the $2^{\text {nd }}$ International Conference on Mechanic Automation and Control Engineering, MACE 2011, Inner Mongolia, China, pp. 2460-2463.

[27] K. El-Rayes and A. Kandil, "Time-cost-quality trade-off analysis for highway construction," J. Constr. Eng. Manage., vol. 131, no. 4, pp. 477-486, 2005. 
[28] Michigan Department of Transportation (MDOT). (2015). Innovative Construction Contracting Guide [Online]. Available:

http://www.michigan.gov/documents/mdot/ Innovative_Construction_Contracting_340000_7.pdf. [Accessed: 4 Aug. 2015]

[29] Minnesota Department of Transportation (Mn/DOT). (2008). Innovative Contracting Guidelines: Office of Construction and Innovative Contracting [Online]. Available: http://www.dot.state.mn.us /const/tools/docs/Guidelines Dec 2008.pdf [Accessed: 4 Aug. 2015).

[30] D. Arditi, C. J. Khisty, and F. Yasamis, "Incentive/disincentive provisions in highway contracts," J. Constr. Eng. Manage., vol. 123, no. 3, pp. 302-307, 1997.

[31] K. El-Rayes, "Optimum planning of highway construction under A + B bidding method," J. Constr. Eng. Manage., vol. 127, no. 4, pp. 261-269, 2001.

[32] J.G. Vogtländer, LCA-based assessment of sustainability: the Eco-costs/V alue Ratio (EVR). Netherlands: VSSD, Science and Technology, Delft Academic Press, 2009.

[33] United States Department of Energy (DOE), "Diesel power: clean vehicles for tomorrow," DOE Energy Efficiency and Renewable Energy Vehicle Technologies Program, 2010.

[34] United States Environmental Protection Agency (EPA), "Cleaner diesels: Low cost ways to reduce emissions from construction equipment," EPA 100-R-07-002, National Center for Environmental Innovation, U.S. EPA, Washington, DC, 2007.

[35] Caterpillar. (2013). 336EH Hydraulic Excavator Product Brocbure [Online]. Available: http://s7d2.scene7.com/is/content/Caterpillar/C811713 [Accessed: 10 Jan. 2016]

[36] Hitachi. (2015). New Generation Hybrid Excavator zb200-5b [Online]. Available: http://www.hitachi.com/environment/showcase/solution/industrial/hybrid_excavator.html

[Accessed: 10 Jan. 2016]

[37] Komatsu. (2001). Mitigating Climate Change through Products and Services [Online]. Available: http://www.komatsu.com/CompanyInfo/csr/2009/pdf/13.pdf [Accessed: 10 Jan. 2016]

[38] M. Ochiai and S. Ryu, "Hybrid in construction machinery," in Proceedings of the 7th JFPS International Symposium on Fluid Power, 15-18 September 2008, Toyama, Japan, pp. 41-44.

[39] Volvo. (2008). Volvo Wheel Loader_l220f Hybrid [Online]. Available: http://www.volvoce.com/SiteCollectionDocuments/VCE/DocumentsGlobal/wheelloaders/brochu reHybridloader_21A1004471_2008-02.pdf [Accessed: 10 Jan. 2016]

[40] DCL International Inc. (DCL). (2015). Typical Conversion Efficiencies [Online]. Available: http://www.dclinc.com/catalyst-specifications/ [Accessed: 18 Jan. 2016]

[41] Johnson Matthey. (2015). Diesel Exbaust Gas Treatment SCRT for Retrofitting [Online]. Available: http://www.jmdpf.com/pdfs-library/Johnson-Matthey-DPF-brochure-2015.pdf [Accessed: 18 Jan. 2016]

[42] Manufacturers of Emission Controls Association (MECA). (2007). Emission Control Technologies for DieselPowered Vebicles [Online]. Available: http://www.meca.org/galleries/files/ MECA_Diesel_White_Paper_12-07-07_final.pdf [Accessed: 18 Jan. 2016]

[43] K. Theinnoi, "The control of nitrogen oxide emission from diesel engine using selective catalyst reduction-SCR," (in Thai) Princess of Naradhiwas University Journal, vol. 4, no. 3, pp. 124-138, 2012.

[44] World Bank. (2014). Reducing Black Carbon Emissions from Diesel Vehicles: Impacts, Control Strategies, and CostBenefit Analysis [Online]. Available: https://openknowledge.worldbank.org /bitstream/handle/10986/17785/864850WP00PUBL010report002April2014.pdf [Accessed: 18 Jan. 2016]

[45] United States Environmental Protection Agency (EPA), "A comprehensive analysis of biodiesel impacts on exhaust emissions - Draft Technical Report," EPA420-P-02-001, Office of Transportation and Air Quality, U.S. EPA, Washington, DC, 2002.

[46] M. Metham and V. Benjaoran, "The assessment of greenhouse gas emissions for evaluating actual road construction operations," in Proceedings of the 31 st Annual Association of Researchers in Construction Management Conference, 7-9 September 2015, ARCOM, Lincoln, U.K., pp. 257-266.

[47] The Intergovernmental Panel on Climate Change (IPCC), "Database on greenhouse gas emission factors (IPCC-EDB)," National Greenhouse Gas Inventories Programme, 2006. 


\section{Appendix A. Notations for the CEP scheme}

The following symbols are used in this paper:

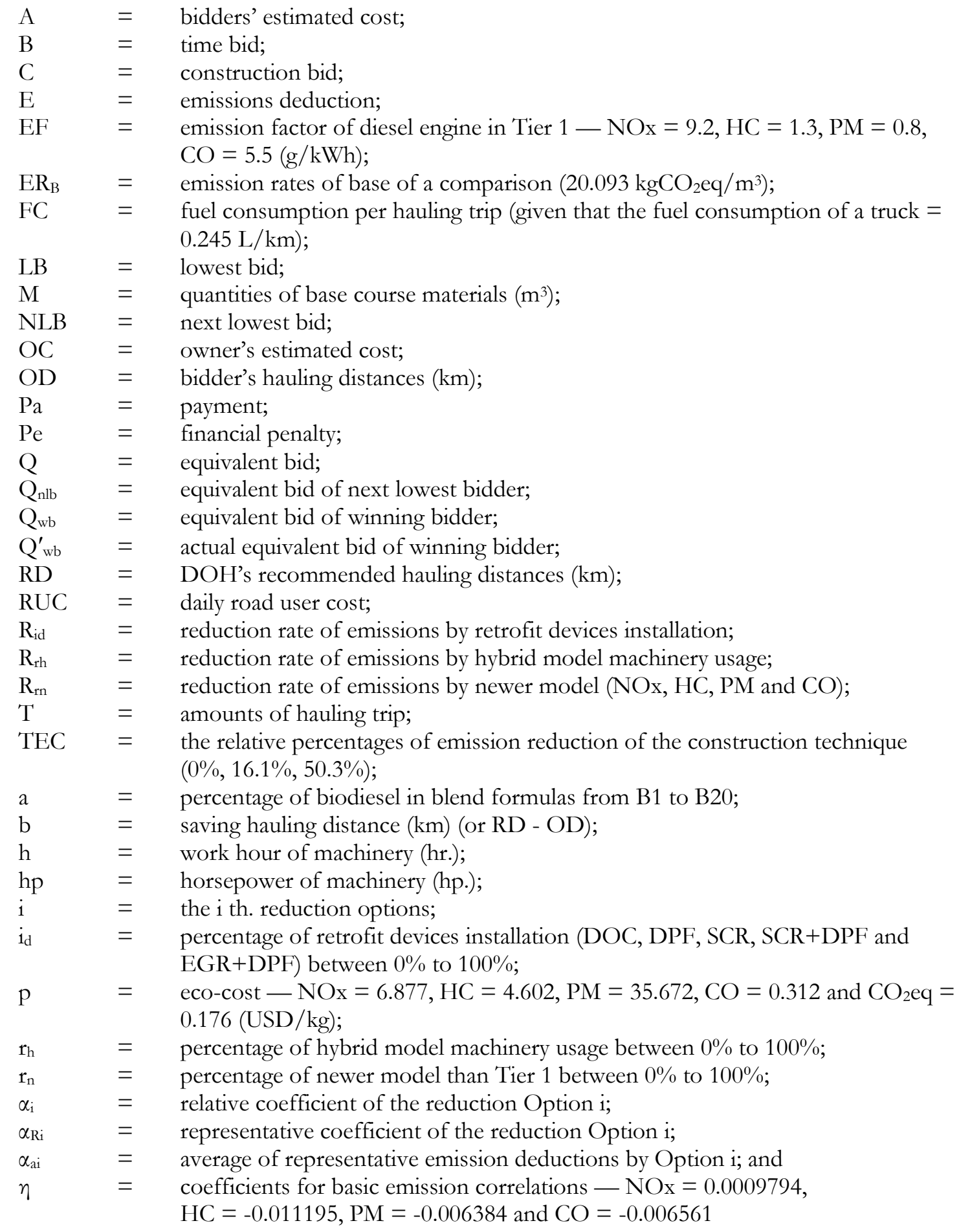

